\title{
New Health Care in Germany - Building of Breast Centers: Reasonable Enhancements or Obsessive Development of Political Health Care in Germany?
}

\author{
Monika Nothacker Dirk Claus Guido Tuschen \\ Westdeutsches Brust-Centrum GmbH, Düsseldorf, Germany
}

Key Words

Breast center - Disease management program .

Certification - Quality assurance - Quality indicators

\section{Summary}

The article elucidates the preconditions for the building of breast units. The Disease Management Program (DMP) Breast Cancer is explained in detail as well as the certification procedure of DKG/DGS. The article comments on the quality indicators of structural, performance and outcome parameters of DMP and certification and how data for this are gained. Specific problems for centers to get data in the German health care system with an ambulant and a clinical sector and possible solutions are pointed out.

\section{Introduction}

In Germany, approximately 50,000 women are diagnosed with breast cancer every year. Approximately 17,000 women die of the disease. The resulting life time deficit in years is 310,000 per year. According to data on breast cancer mortality from 17 North and West European countries, Germany ranks at position 9 with a rate of $23.74 / 100,000$. The country with the lowest mortality rate is Sweden with 17.48/100,000 [1] (mortality rate standardized for age). Simultaneously, in 2000, the advisory council for the evaluation of the development in health care (Sachverständigenrat, SVR) described breast cancer care in Germany as a coexistence of oversupply, undersupply and missupply [2].

\begin{tabular}{|c|c|}
\hline KARGER & (C) 2006 S. Karger GmbH, Freiburg \\
\hline $\begin{array}{l}\text { Fax +497614520714 } \\
\text { E-mail Information@Karger.de } \\
\text { www.karger.com }\end{array}$ & $\begin{array}{l}\text { Accessible online at: } \\
\text { www.karger.com/brc }\end{array}$ \\
\hline
\end{tabular}

\author{
Schlüsselwörter \\ Brustzentrum - Disease Management Programm . \\ Zertifizierung · Qualitätssicherung · Qualitätsindikatoren
}

\section{Zusammenfassung}

In diesem Artikel werden die Voraussetzungen für das Entstehen von Brustzentren aufgezeigt. Das Disease Management Programm Brustkrebs wird detailliert dargestellt, ebenso wie das Zertifizierungsverfahren der DGS/ DKG. Insbesondere die unterschiedlichen Struktur-, Prozess- und Ergebnisqualitätsindikatoren der beiden Verfahren und die Art der Datenerhebung dafür werden erläutert. Es wird aufgezeigt, welche spezifischen Probleme Zentren im deutschen Gesundheitssystem mit ambulantem und stationärem Sektor haben, die zur Qualitätssicherung erforderlichen Daten zu gewinnen. Mögliche Lösungen werden skizziert.

To optimize care for breast cancer patients, special breast units have been built since 2002. The following article elucidates the background of the center construction and discusses the quality indicators used. Problems and consequences of the development of breast centers in relation to the German health care system are presented.

\section{Fundamentals of Breast Unit Development in Germany}

Both, the Disease Management Program (DMP) Breast Cancer and the certification procedure by the German Oncologi-

Dr. med. Monika Nothacker, MPH 
cal Society (Deutsche Krebsgesellschaft, DKG) and the German Society of Mastology (Deutsche Gesellschaft für Senologie, DGS) are fundamental for the development of breast units in Germany (accreditation of breast units by the European Society of Mastology, EUSOMA, is not discussed in this article).

\section{Disease Management Program Breast Cancer}

To put an end to the situation analyzed by the SVR in 2000, a nationwide DMP for breast cancer therapy - DMP Breast Cancer - was presented in 2002 (alongside a DMP for diabetes mellitus type II). The implementation of DMPs for widespread diseases was recommended by Prof. Dr. K. Lauterbach [3], one of the economic advisors of the Ministry of Health. The initial aim of DMPs was to link programs for chronic diseases with the risk structure adjustment of the insurance companies to enhance the latter. DMPs provide insurance companies with an incentive to look after patients with so-called 'bad risks', because an insurance company obtains a certain amount of money for each patient who is enrolled in a DMP. Before then, only age and female gender were taken into account for risk structure adjustment [4].

DMPs claim to improve general patient care. Guideline-based therapy is aimed at following a cross-sector concept [5]. Besides improving the quality of care by using evidence-based standards, patients should be guided throughout the different parts of therapy by one coordinating doctor. The legal basis for DMPs is formed by $\S 137 \mathrm{f}$ of the German Social Code Book V (Sozialgesetzbuch, SGB V), 2001, which is concerned with structured care programs for chronic diseases. Breast cancer - which is not a typical chronic disease - was selected for DMP by request of Health Minister U. Schmidt in consideration of the survey of the SVR and for general political reasons (verbal information by Dr. L. Hansen, head of the Association of Statuary Health Insurance Physicians (Kassenärztliche Bundesvereinigung, KBV), North Rhine-Westphalia, 2003). The Federal Coordination Committee - since 2004 named Federal Joint Committee (Gemeinsamer Bundesausschuss, GBA) - of the Self-Administration (Selbstverwaltung) has defined criteria for adequate, guideline-based therapy within DMPs. The programs have been set up for an initial period of 3 years after which they will be evaluated.

Since DMPs are authorized by the insurance companies, the federal social insurance authority (Bundesversicherungsamt, BVA) is responsible for accreditation, and each insurance company has to apply directly for accreditation. Accreditation is only valid for a particular federal state, and does not apply nationwide. By October 2005, the BVA had authorized more than 1,500 programs for breast cancer. The BVA is also responsible for the final evaluation of the programs [6]. Meanwhile, in each federal state, the results of the DMPs are collected. Hospital and office-based physicians should fill out questionnaires which are sent to DMP data centers. Each federal state has its own DMP data center. For reasons of data protection, the data is deleted after 5-7 years. For the patients, the participation in a DMP is voluntary [5]. So far, only 1 report on the DMP Breast Cancer has been published on a federal level, with data from North Rhine-Westphalia [7]. The data was collected from 2002 to 2004. Of approximately 20,000 potential patients, $28.5 \%$ had been enrolled in the DMP, resulting in a selection bias of approximately $70 \%$. We do not know whether enrolment in a DMP results in better therapy outcome or not. Also, it is yet impossible to obtain complete data for a particular breast center, as not all patients take part in the DMP. Nonetheless, for North Rhine-Westphalia, reports on breast centers with data from 2003-2005 were made. However, they have not yet been released (verbal information by Dr. L. Altenhofen, central institute of insurance companies (Zentralinstitut für die kassenärztliche Versorgung, ZI), May 2006). In summer 2006, the insurance company AOK will publish a report with the results of 1,5 million DMP patients (diabetes and breast cancer). The data is analyzed by 3 different scientific institutes. The BVA will take this report as a basis for the re-admission of the programs [8]. By the end of May 2006 , information on this analysis was not yet available.

\section{German Certification of Breast Units}

The implementation of the DMP Breast Cancer is accompanied - but has been independently developed - by the establishment of certified breast centers through the respective professional oncological associations DKG and DGS. Certificates are given if certain quality requirements are fulfilled. The quality criteria have been defined by an expert commission of the 2 societies (comprising 16 members), according to evidence-based knowledge. One requirement for certification is that the department has performed general quality assurance measures (so-called ISO or KTQ certification). The special certification for a breast unit is added. The professional societies founded a corporation which manages certification performance by sending experts to the units [9]. The experts have to work out a report concerning structure and performance of the breast unit using a defined plan. A preliminary certification is given for 1 year, final certification can be acquired after 3 years. The first breast unit in Germany was certified in 2002. By April 2006, 109 breast units were certified according to the principles of DKG/DGS [10].

Being approved as a DMP unit is economically necessary for breast units. Except for North Rhine-Westphalia and BadenWuerttemberg, certification is voluntary. In Baden-Wurttemberg, a DMP breast unit has to be certified according to the DKG/DGS, or it has to be an oncological center ('Onkologischer Schwerpunkt'), or it must have at least 1 surgeon with a record of at least 50 primary operations [11]. In North RhineWestphalia, the Ministry of Health together with the Self-Administration have defined an independent certification procedure in which the location of the breast units is determined in the state hospital plan. Here, certification is granted by the Medical Association of North Rhine-Westphalia. 


\section{Quality Indicators for DMP Breast Units and Certification}

To avoid going beyond the scope of this article, only the most important quality indicators are discussed.

\section{Structural Quality Indicators}

The following indicators are required for both DMP and certification.

1. Minimal workload per center: This is the first and most crucial structural requirement for the health care system in Germany. DKG/DGS experts as well as the people responsible for the DMP consider a minimum of 150 newly diagnosed breast cancer cases per operating center per year as an essential structural quality criterion. This is in accordance with EUSOMA [12] and is based on the results of the retrospective study by Roohan et al. [13] (level of evidence III). This study shows that survival of breast cancer patients is best in hospitals with a workload of 150 or more breast cancer cases per year. EUSOMA also considers that treating less than 150 cases a year is not economic [12]. Criticism has arisen in Germany concerning evidence for minimum required quantities of breast cancer operations [14]. Nevertheless, the building of special breast units results in a clear concentration of patients at certain locations. Until 2000, breast cancer in Germany was commonly treated in small units, as shown by data from the federal state of Hessen: $20 \%$ of patients were treated in 55 gynecological departments with less than 50 operations and $25 \%$ in 23 departments with 50-149 operations per year. Only 55\% of patients were treated in 12 hospitals with 150 or more operations per year [15]. These figures, which are also representative of the structural situation in other federal states, show that building breast units means a dramatic change for gynecologic departments. So the ongoing establishment of breast centers within the scope of the state hospital plan of North RhineWestphalia will lead to the fact that by 2010, of approximately 210 institutions which were performing breast cancer operations in 2004 only $80-90$ will remain. Similar processes can be observed in other federal states. For example, in Bavaria the Self-Administration conducted a selection of locations, and only 43 of 200 institutions were authorized for DMP [16]. In Berlin, only 7 of 33 former breast cancer surgery-performing departments were chosen by the insurance companies to be DMP breast units. Each hospital corporation was allowed to have 1 breast unit. According to a study by Ernst and Young in 2005 [17], more than $25 \%$ of all in-patient institutions will be closed by 2020. Regarding the development of center building since 2000, this result will be achieved even earlier for breast cancer-treating departments. Therefore, it is essential to measure performance and outcome quality of the remaining departments to ensure high quality. Unfortunately, it is almost impossible to compare the work of former departments with actual breast units because of the lack of exact data, especially for outcome quality.
2. Minimal workload per surgeon: In addition to limitations concerning the actual breast units, there are limitations concerning the surgeons. This follows the retrospective study by Sainsbury et al. [18], which showed that 5-year survival was better in patients treated by 17 surgeons with a record of 30 or more operations per year than in patients treated by 120 surgeons performing less than 29 operations. In Germany, a minimum of 50 operations per surgeon has been assessed. Subsequently, a breast unit requires 3 surgeons for a workload of up to 200 cases per year. For gynecological departments this means that breast surgery can only be performed by a small number of experts, and specialization is possible for very few surgeons only.

3. Interdisciplinary cooperation and communication in tumor boards: To avoid inadequate therapy (including surgery and adjuvant therapy, such as radio- and chemotherapy), interdisciplinary cooperation and communication are required. The DMP demands a weekly case-related tumor conference for which there are no further specifications [19]. For certification, the requirements are much more detailed. In the beginning, $20 \%$ and after 3 years, $50 \%$ of pre- and postoperative patients must be discussed by the tumor board. All members of the interdisciplinary team - surgeon, radiologist, gynecological oncologist, oncologist, radiographer and pathologist must be present. There must be a network plan concerning internal and external communication, and all staff members must sign cooperation contracts. The network plan must also include communication and cooperation structures for external physicians, psychologists, social workers and rehabilitation centers [20]. Structural quality of DMP clinics is also the responsibility of the interdisciplinary team, but no detailed network plan or written contracts are required [19]. Before the establishment of breast units, the cooperation and communication between specialists depended on the voluntary organization of each gynecological department as well as on the cooperation of the other parties, such as external physicians. All in all, certification criteria for this cooperation are much more clear and detailed than DMP criteria.

4. Special structural indicators for DMP: At least $70 \%$ of patients should undergo surgery in a DMP breast unit, and $60 \%$ should complete and correct documentation. $90 \%$ of patients should accept an informative preoperative conversation, and $90 \%$ should arrange a postoperative appointment. There is no explanation of the percentage given for the first 2 indica-

\section{Table 1. Performance indicators - DMP [19]}

At least $55 \%$ breast conserving surgery

At least $80-95 \%$ axillary dissection in invasive carcinoma with 10 lymph nodes or sentinel nodes (documentation possible since June 2005)

$55-75 \%$ adjuvant systemic therapy if patient is lymph node-positive 
Table 2. Performance indicators - certification [20]

\begin{tabular}{|c|c|c|}
\hline Indicators & $\begin{array}{l}\text { Primary } \\
\text { certification }\end{array}$ & $\begin{array}{l}\text { Renewal } \\
\text { after3 years }\end{array}$ \\
\hline \multicolumn{3}{|l|}{ Operative indicators } \\
\hline $\begin{array}{l}\text { Axilla dissection in cases of invasive breast cancer as sentinel } \\
\text { node biopsy (at least } 1 \text { lymph node) or classical dissection } \\
\text { (level } 1 \text { and } 2,>10 \text { nodes); if sentinel node is positive: } \\
>10 \text { nodes }\end{array}$ & $85 \%$ & $95 \%$ \\
\hline Patients satisfied with cosmetic result (questionnaire) & $70 \%$ & $80 \%$ \\
\hline Re-operation due to complications during or after surgery & $<5 \%$ & \\
\hline Wound infections & $2.5-5 \%$ & \\
\hline $\begin{array}{l}\text { Consecutive operations per case (not including surgery due to } \\
\text { complications), n }\end{array}$ & maximum 3 & \\
\hline In situ cancer at first operation & $>10 \%$ & $>15 \%$ \\
\hline Discovered carcinoma in open biopsy, malign/benign ratio & $1: 2$ & $1: 1-2: 1$ \\
\hline $\begin{array}{l}\text { Postoperative preparation - microlime radiography after } \\
\text { preoperative labeling }\end{array}$ & $>95 \%$ & \\
\hline Breast-conserving therapy ( pT1) & $>50 \%$ & $>70 \%$ \\
\hline Mastectomy as primary operation & $<50 \%$ & $<30 \%$ \\
\hline $\mathrm{R} 1$ resections, $\mathrm{n}$ & not defined & \\
\hline Interventions per year (benign cases included), $\mathrm{n}$ & not defined & \\
\hline \multicolumn{3}{|l|}{ Adjuvant systemic indicators } \\
\hline Adjuvant chemotherapies per year, $\mathrm{n}$ & 50 & \\
\hline Palliativ chemotherapies per year, $\mathrm{n}$ & 50 & \\
\hline Chemotherapy in receptor-negative cancer (up to 70 years of age) & $>70 \%$ & $>80 \%$ \\
\hline Patients with adjuvant chemotherapy (up to 70 years of age) & $>70 \%$ & $>95 \%$ \\
\hline Out-patient chemotherapies & $>60 \%$ & \\
\hline Treatment series per year, $\mathrm{n}$ & 200 & 400 \\
\hline Adjuvant antihormonal therapies per year, $\mathrm{n}$ & $>50$ & $>100$ \\
\hline Palliative antihormonal therapies per year, $\mathrm{n}$ & $>50$ & $>100$ \\
\hline Endocrine therapy in receptor-positive breast cancer & $>75 \%$ & $>95 \%$ \\
\hline Participation in clinical trials & $20 \%$ & $30 \%$ \\
\hline \multicolumn{3}{|l|}{ Adjuvant radiological indicators } \\
\hline Adjuvant radiation after breast-conserving therapy & $>85 \%$ & $>95 \%$ \\
\hline Adjuvant radiation after mastectomy, $\mathrm{n}$ & $30 \%$ & $>40 \%$ \\
\hline Sentinel scintigraphy, $\mathrm{n}$ & 20 & 50 \\
\hline Total scintigraphy, $\mathrm{n}$ & 200 & 400 \\
\hline \multicolumn{3}{|l|}{ Pathological indicators } \\
\hline Minimum of analyzed breast cancer preparations per year, $\mathrm{n}$ & 100 & 200 \\
\hline Histological analyzes of breast tissue per year, $\mathrm{n}$ & 300 & 500 \\
\hline Lymph nodes examined, $\mathrm{n}$ & $>10$ & \\
\hline Specification of hormonal receptors of breast cancer tissue & $>80 \%$ & $>90 \%$ \\
\hline Specification of security interspace & $>80 \%$ & $>95 \%$ \\
\hline Specification of $\mathrm{pT}$ und $\mathrm{pN}$ in invasive breast cancer & $100 \%$ & \\
\hline
\end{tabular}

tors. Whether a formal appointment for an informative conversation or a postoperative visit is a criterion of quality, is doubtful.

\section{Performance Indicators}

The performance indicators for DMPs (table 1) and certification (table 2) are presented separately. For certification, a lot more information has to be collected than for the DMP. There are performance quality indicators for each part of breast cancer care. A breast unit has to present all data to the experts.

\section{Outcome Indicators}

For DMPs, improvement of disease-free survival and quality of life are the outcome indicators (table 3) [19]. Quality of life is surveyed with an extra questionnaire. Although it is an important goal of DMP, the standardized documentation does not comprise questions on quality of life. Also, for the outcome indicators, certification measurements are more specified than DMP indicators [20]. Concerning quality of life, a breast unit has to use a questionnaire at least 3 months a year for all patients and present it to the experts. 
Table 3. Outcome indicators for certification

\section{Indicators}

Relapse rate after breast conserving surgery after 10 years

Relapse rate after mastectomy after 10 years

Annual disease-free survival for all breast cancer cases of all stages

Annual overall survival for all breast cancer cases of all stages

Time of occurrence and extent of relapse dependent on type of operation and tumor stage

Time of occurrence and extent of distant metastasis dependent on type of operation and tumor stage

Mortality rate of annual cohorts

\section{Quality Improvement by the Statutory Health Insurance Modernization Act (2000)}

The Self-Administration was assigned by the government in 2000 to control quality and transparency by analyzing data from each clinic ( $\$ 137$ SGB V). This law resulted in the formation of the federal agency of - external and comparative quality assurance (Bundesgeschäftsstelle Qualitätssicherung, BQS) [21]. Here, data of the clinical sector are analyzed annually, including data on the diagnosis and therapy of breast cancer. Patient data can be transferred within the time given by the diagnosis-related group (DRG) of the disease treated. For the assurance of quality of care, it is a disadvantage that if a patient is admitted several times for the same disease, the individual hospital stays cannot be put together. Hence, longitudinal data analysis is not possible. According to the statutory health insurance modernization act (Gesetz zur Modernisierung der gesetzlichen Krankenversicherung, GMG) 2000 , insurance companies are allowed to negotiate directly with the care providers in order to define quality and transparency of diagnosis and treatment in particular contracts ( 140 SGB V, integrated care). However, these 2 quality assurance measures did not lead to concentration of care.

\section{Lessons to be Learnt from the Development of Breast Centers within the Structures of the German Health Care System}

Mainly due to the DMP, there was an impetuous concentration of breast units because of structural requirements. That even with a special workload, an interdisciplinary breast center can improve the quality of the breast cancer treatment, is evident in several other countries [22]. Certainly, therapy according to $\mathrm{S} 3$ guidelines is of clear advantage to the patients [23]. In this respect, the establishment of breast centers represents an advancement. However, data management and quality assurance of the DMP is not primarily aimed at breast units. Quality of care is generally measured for registered persons, though the quote of registration is quite low. Follow-up data are mostly gathered by external physicians, but is not necessarily sent to the operating breast unit. In some federal states, the role of the office-based physician will be strengthened by the DMP, in other states a rather clinic-oriented performance is conducted (e.g. Berlin). A reliable cooperation of both parties is still not guaranteed because of financing structures and different interests. Data management seems predominantly useful to the insurance companies but bears high expenses. Hence, in its 2003 report, the SVR judged the DMP structure as rather negative [24]. The patterns chosen for quality indicators are not very specified, and classical outcome parameters are not measured. Data are deleted after some years, and a transfer to cancer registers is not possible which is justified by issues of data protection.

The approach is quite different for certification. The associations DKG and DGS instruct the certified centers to gain their own data. Quality indicators for either structural or performance and outcome quality are quite detailed, although in some patterns clear definitions are missing. The breast unit is asked to use a special documentation system for the data. A transfer of the data to cancer registries is possible with those special systems, but is not yet realized for all systems and for all federal states. Firstly, it is important that the breast unit as care provider hold its own data. But within the structures of the German health care system, collecting data for special units is difficult, especially - as already mentioned - because of the strict separation of the office-based and clinical sector. In the UK, a patient undergoing surgery in a certain breast unit will usually come back to this unit for follow-up or reoperation. In Germany, patient follow-up is done by external physicians who do not necessarily send the data to the operating breast unit. So outcome data are often missing. Also, data on adjuvant therapy - if done by external oncologists or radiographers - may be missing. Even the data transfer between different departments is not always guaranteed. The integration of oncology and radiation therapy is often difficult. A breast unit has to operate as an interdisciplinary unit, and this activity must include data collection. In the process of concentration of care, it is nevertheless essential that a breast center is aware of its own process and outcome quality (relapse rate and mortality rate), which is also demanded by the certifying associations.

Clinical cancer registers could help breast units to obtain outcome data. Unfortunately, the registration of relapse and mortality rate is very different in the various federal states. The clinical tumor register of Munich represents a functioning register with comparatively very good data. Information about patients is send in not only by external doctors and clinics, but also by pathologists. Therefore, of more than $70 \%$ of patients with breast cancer in this register, local or regional relapse is known, although registration of distant metastases still remains difficult. Mortality is known for almost all patients (verbal information by Prof. D. Hoelzel, May 2006, and [25]). Data can be called up by clinicians who can log in using a special 
password. This service is sponsored by the Bavarian Ministry of Health rather than the insurance companies.

For certification, experts assess a single center. There might be a certain bias caused by the subjectivity of the experts who might judge breast centers differently. Thus, it is of high interest for breast units to compare each others achievements. This is possible by sharing data for benchmarking. The WBC (Westdeutsches Brustcentrum) has been operating such benchmarking since 2000, with now more than 220 breast units taking part. Every 6 months, a comparative report is submitted [26]. When the performance of quality indicators is measured for a group of (or all) breast centers, the impact of the quality indicator itself can be judged, which is very impor- tant. Also, difficulties in obtaining data might be a general problem - like demonstrated for data of adjuvant therapy or outcome data - and can be diagnosed as such if breast units are compared. Politicians should both demand transparency of quality and enable it. During the establishment of breast centers, it was left unclear that the clinical and external sector must both be integrated. Breast centers must be supported in their efforts to construct interdisciplinary work much more efficiently. At present, DMP data collection is neither sufficient nor efficient enough. Therefore, presenting data of not only one but all breast units together is very important to illustrate the situation. As the centralization process proceeds for other tumor entities, networking in breast cancer care is exemplary.

\section{References}

1 Globocan: Rohe und altersstandardisierte Mortalität an Brustkrebs in West- und Nordeuropa, 2002. www-dep.iarc.fr

2 Sachverständigenrat für die konzertierte Aktion im Gesundheitswesen: Bedarfsgerechtigkeit und Wirtschaftlichkeit. Band III : Über-, Unter- und Fehlversorgung. Baden-Baden, 2002.

3 Lauterbach K, Wille E: Modell eines fairen Wettbewerbs durch den Risikostrukturausgleich. Gutachten im Auftrag des Verbands der Angestellten Krankenkassen e.V., des Arbeiter-Ersatzkassen Verbands e.V., des AOK-Bundesverbandes und des IKK Bundesverbandes, 2000.

4 www.die-gesundheitsreform.de/glossar/risikostrukturausgleich.html

5 www.aok-dmp.de

6 www.bva.de (fachinformationen/disease management programme)

7 Qualitätssicherungsbericht 2004: Disease-Management-Programme in Nordrhein, Nordrheinische Gemeinsame Einrichtung Disease Management Programme GbR, 2005.
8 Kosten-Nutzen-Studie zu DMP: www.aok-gesundheitspartner.de/bundesverband/dmp

9 www.onkozert.de

10 www.senologie.org/brustzentren/brust_zbrustzenten.htm

11 www.kvnw.info/publikationen/sonstigepub/DMPBKr2.pdf

12 EUSOMA: The requirements of a special breast unit. Eur J Cancer 2000;36:2288-2293.

13 Roohan PJ et al.: Hospital volume differences and five-year survival from breast cancer. Am J Public Health 1988;88:454-457.

14 Geraedts M: Evidenz zur Ableitung von Mindestmengen in der Medizin. Gutachten im Auftrag der Bundesärztekammer, 2004. www.bundesaerztekammerde

15 Hessisches Statistisches Landesamt: Operationsleistung von Kliniken in Hessen im Jahr 2000.

$16 w w w . k v b . d e$

17 Ernst \& Young: Gesundheitsversorgung 2020. Studie, 2/2005. www.ey.com
18 Sainsbury R, Haward B, Rider L, Johnson C, Round C: Influence of clinician workload and patterns of care on survival from breast cancer. Lancet 1995,345:1265-1270.

19 Praxismanual DMP Brustkrebs. Berlin, 2003.

20 www.senologie.org

21 www.bqs-online.de

22 Kingsmore D, Hole D, Gillis C: Why does specialist treatment of breast cancer improve survival? The role of surgical management. Brit J Cancer 2004;90: 1920-1925.

23 Herbert-Croteau N et al.: Compliance with consensus recommendations for systemic therapy is associated with improved survival of women with nodenegative breast cancer. J Clin Oncol 2004;22: 3685-3693.

24 Sachverständigenrat für die konzertierte Aktion im Gesundheitswesen: Finanzierung, Nutzerorientierung und Qualität. Band II: Qualität und Versorgungsstrukturen. Baden-Baden 2003, p. 89

25 www.med.uni-muenchen.de/trm/daten

26 www.brustcentrum.de 